\title{
Recent progress in immobilization of late-transition-metal complexes with diimine ligands for olefin polymerization
}

\author{
WU Wei, JIANG Yan, WU Hao, LV ChunSheng, LUO MingJian, NING YingNan \& \\ MAO GuoLiang ${ }^{*}$ \\ Provincial Key Laboratory of Oil and Gas Chemical Technology, College of Chemistry and Chemical Engineering, Northeast Petroleum \\ University, Daqing 163318, China
}

Received October 23, 2012; accepted November 30, 2012

\begin{abstract}
Late-transition-metal (LTM) catalysts are a family of very flexible ethylene polymerization catalysts because their catalytic performance can be easily adjusted by modifying the ligand structure. Their less oxyphilicity character, which may promote the production of copolymers from ethylene and polar comonomers, is another aspect that attracts much attention in both academic and industrial fields. The immobilization of LTM catalysts on spherical supports is a crucial step prior to their use in the industrial processes of gas-phase or slurry polymerizations. This paper reviews recent developments in supported LTM catalysts for olefin polymerization, and summarizes loading methods and mechanisms of the immobilization of LTM catalysts on inorganic, organic, and inorganic-organic materials, and the effects of immobilization on catalytic activity, polymerization mechanism, and polymer morphology.
\end{abstract}

late-transition-metal complexes, diimine, immobilization, olefin polymerization

Citation: Wu W, Jiang Y, Wu H, et al. Recent progress in immobilization of late-transition-metal complexes with diimine ligands for olefin polymerization. Chin Sci Bull, 2013, 58: 1741-1750, doi: 10.1007/s11434-013-5748-8

Transition-metal catalysis plays a key role in the polyolefin industry. The discovery of Ziegler-Natta catalysts revolutionized the industry. Titanium- and zirconium-based metallocene systems are still the workhorses in the manufacture of commodity polyolefin materials [1-3]. In contrast to complexes of early transition-metals, the late-transitionmetal (LTM) complexes reported by Brookhart [4] and Gibson [5] are attracting increasing attention because of the easy preparation and modification of their Schiff base ligands [6-8]. Recently, according to different coordination forms, some LTM-based complexes with novel diimine ligands containing $\mathrm{Fe}$ [9-12], Co [13,14], Ni [15-21], Pd $[22,23]$ are applied to olefin polymerization. The products obtained using such catalysts can be changed from polyethylene $(\mathrm{PE})$ to oligomers by tuning the steric and electronic properties of the ligands [24]. Bulky complexes can produce high-molecular-weight branched PE, without the addition of

*Corresponding author (email: maoguoliang@ @epu.edu.cn) $\alpha$-olefin comonomers, in the presence of methylaluminoxane (MAO). Some bulky catalysts with special backbone such as camphyl and acenaphthyl show highly thermal stability and good control ability for olefin polymerization [25]. Late transition-metals are more suitable for the copolymerization of ethylene with commercial polar olefins because of their better tolerance of polar functional groups. Only amorphous polymers can be obtained if the polymerization is catalyzed by homogeneous catalysts, inevitably leading to reactor fouling in industrial units. To meet the requirements of continuous industrial gas-phase or slurry polymerization units, a crucial step for the industrialization of LMT catalysts is the immobilization of such catalysts on spherical supports to obtain morphologically uniform polymer particles.

\section{Immobilization methods}

There are three major supporting methods applicable for the 
immobilization of LTM catalysts. The first method is direct immobilization of the LTM catalysts on carriers by physical adsorption; this method is very commonly used because it is easy to operate and inexpensive [26]. Catalysts supported by physical adsorption easily leach from the supports during polymerization and cause reactor fouling. The second method is to pretreat the supports with MAO or an alkylaluminum, and then immobilize the LTM catalysts on supports through ionic bonds formed by multicoordinated "crown" aluminoxane complexes and the active sites of the catalysts (Figure 1) [27]. The third method is immobilization of the catalyst ligands using special functional groups on supports pretreated with alkylaluminum through covalent bonds. This method is more effective than previously reported methods for reducing leaching phenomena.

\section{Late-transition-metal catalysts immobilized on inorganic carriers}

\subsection{Late-transition-metal catalysts immobilized on $\mathrm{SiO}_{2}$ supports}

Silica is the most common inorganic support; it provides a high specific surface area, suitable distributions of pore volume and size, good mobility, an appropriate average grain diameter, and good mechanical strength. Ma et al. [28] prepared supported Fe-based diimine catalysts by immobilization of 2,6-bis[1-(2,6-diisopropylphenylimino)ethyl]pyridine iron chloride (I) on $\mathrm{SiO}_{2}$ treated with MAO. They used X-ray photoelectron spectroscopy to trace the changes in the binding energies of different elements of the catalysts during the support process. The results confirmed that the immobilization of the Fe-based diimine catalysts on $\mathrm{SiO}_{2}$ is the result of the bridging effect of MAO. Compared with homogeneous catalysts, the supported catalysts had higher catalytic activities, even at low $\mathrm{Al} / \mathrm{Fe}$ ratios, and performed more stably. The molecular-weight of the PE obtained was two to three times higher than that obtained under homogeneous conditions. The melting temperature was about $10^{\circ} \mathrm{C}$ higher and the particle morphology was better. Xu et al. [27] immobilized the catalysts mentioned above on a novel layered calcosilicate treated with MAO, and explained the bridging effect of MAO. MAO captured hydroxyl groups on the $\mathrm{SiO}_{2}$ surface to form multicoordinated "crown" aluminoxane complexes, which could immobilize the Fe-based diimine catalysts in the "crown" through ionic bonds, giving supported catalysts.

Earlier, Soga et al. [29] prepared a series of metallocene catalysts with special functional groups to immobilize metallocene catalysts on $\mathrm{SiO}_{2}$ supports through covalent bonds. In recent years, similar methods have been used to prepare supported LTM catalysts. Compared with the ionic-bond supporting method, covalent bonds could give more stable attachment of active centers to the support. Some studies suggested that covalent linking of soluble metal complexes to the support was the most effective way to reduce leaching [30,31], and the negative influence on the active sites was relatively small. Schrekker et al. [32] synthesized $\alpha$-diimine nickel precatalysts with an amino or hydroxyl functionality at the $p$-aryl position and precatalysts with one or two hydroxyl functionalities in the alkyl backbone (Figure 2).

The surface hydroxyl groups of $\mathrm{SiO}_{2}$ were treated with trimethylaluminum (TMA), $\mathrm{SiCl}_{4}$, or $\mathrm{BCl}_{3}$ to form the linking part, which could react with the amino or hydroxyl functionalities of precatalysts to link the precatalysts with $\mathrm{SiO}_{2}$ through covalent bonds; treatment with TMA was the most effective. Ethylene-slurry polymerization showed that the supported catalysts had high activities even at low $\mathrm{Al} / \mathrm{Ni}$ ratios. The productivity increased steadily as the ethylene pressure increased from 1 to $4.5 \mathrm{MPa}$, and reached 6.0 kg-PE/g-catalyst at $4.5 \mathrm{MPa}$ and $80^{\circ} \mathrm{C}$. No reactor fouling as a result of catalyst leaching was observed.

LTM catalysts with different structures (Figure 3) were synthesized by Choi and Soares [33]. 1 was immobilized on the surface of $\mathrm{SiO}_{2}$ by ionic bonds because of the absence of functionalities that can form covalent bonds with linking groups; 2 and 3 were immobilized on $\mathrm{SiO}_{2}$ treated with alkylaluminum through covalent bonds.

Among these supported catalysts, 1 was partially extracted

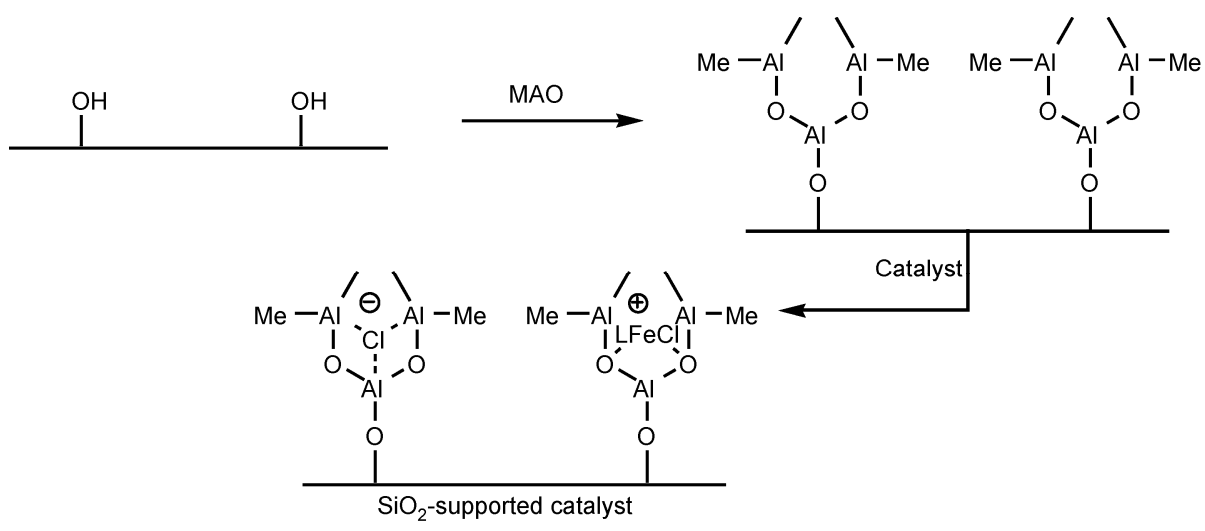

Figure 1 Mechanism of support of Fe-based diimine catalyst on $\mathrm{SiO}_{2}$. 


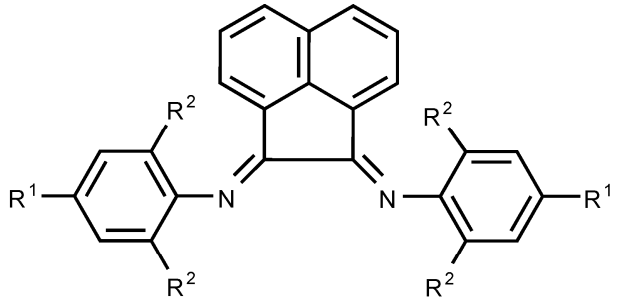

$\mathrm{R}^{1}=\mathrm{CH}_{2}\left(3,5-\mathrm{Me}_{2}-\mathrm{Ph}\right) \mathrm{NH}_{2}, \mathrm{R}^{2}=\mathrm{Me}$

$\mathrm{R}^{1}=\left(\mathrm{CH}_{3}\right)_{3} \mathrm{OH}, \mathrm{R}^{2}=\mathrm{Me}$

$\mathrm{R}^{1}=\left(\mathrm{CH}_{3}\right)_{3} \mathrm{OH}, \mathrm{R}^{2}=i-\mathrm{Pr}$

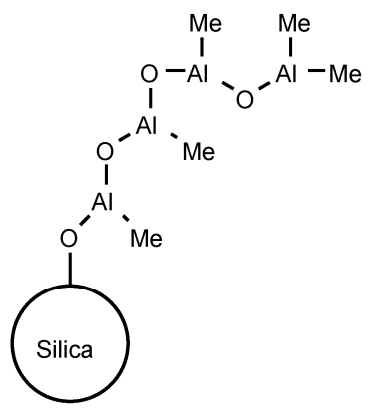

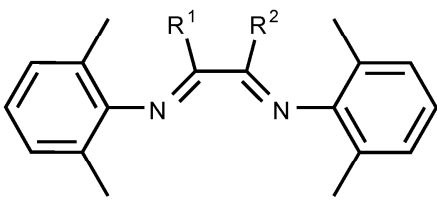

$\mathrm{R}^{1}=\left(\mathrm{CH}_{2}\right)_{7} \mathrm{OH}, \mathrm{R}^{2}=\mathrm{Me}$

$\mathrm{R}^{1}=\left(\mathrm{CH}_{2}\right)_{7} \mathrm{OH}, \mathrm{R}^{2}=\left(\mathrm{CH}_{2}\right)_{7} \mathrm{OH}$

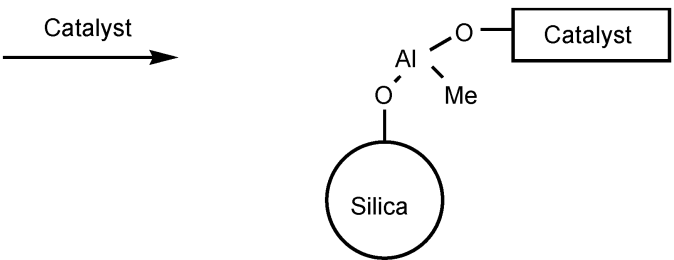

Figure 2 Homogeneous catalysts and supported catalysts.

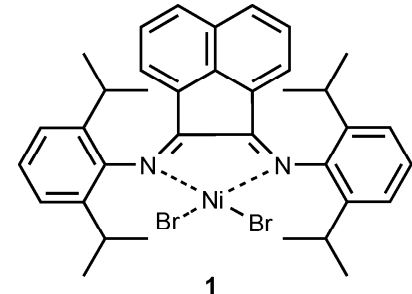

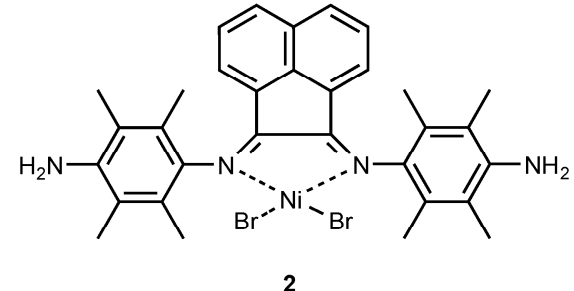

2<smiles>Cc1c(C)c(N(c2c(C)c(C)c(C)n2-c2c(C)c(C)c(N)c(C)c2C)[N+](C)(Br)Br)c(C)c(C)c1N</smiles>

3

Figure 3 Structures of 1-3.

from the $\mathrm{SiO}_{2}$ surface during the polymerization as a result of the weak ionic interactions between the active sites and the support surface; this led to a poor morphology. The $2 / \mathrm{SiO}_{2}$ and $3 / \mathrm{SiO}_{2}$ catalytic systems, supported by covalent bonds, resulted in higher activities and better morphologies. In some cases, even if covalently attached supported catalysts were used for slurry polymerization, there was still a potential risk of reactor fouling as a result of leaching of weakly attached catalyst species when alkylaluminum activators were used. In addition, to take advantage of existing heterogeneous polymerization plant infrastructure, costly activators should be avoided. Considering the above two points, the researchers added bulky anionic borates such as $\mathrm{B}\left(\mathrm{C}_{6} \mathrm{~F}_{5}\right)_{4}{ }^{-}$as internal activators during preparation of the supported catalysts to replace the extra activators in the polymerization process; higher activities and well-controlled spherical morphologies were obtained.

With the aim of achieving higher loadings of active centers in $\mathrm{SiO}_{2}$-supported catalysts reported in previous studies [34,35], Zheng et al. [36] modified the diimine ligands by hydrosilylation of bis(imino)pyridyl containing an allyl group with dichloromethylsilane to introduce $\mathrm{Si}-\mathrm{Cl}$ endgroups; these end-groups could react with $-\mathrm{OH}$ groups on the $\mathrm{SiO}_{2}$ surface. They then prepared a novel series of supported LTM catalysts by coordination reactions of metal compounds with ligands attached to $\mathrm{SiO}_{2}$. The metal active center loading of the supported catalyst was $45.9 \mathrm{mg}-\mathrm{Fe} / \mathrm{g}$ catalyst, about four times higher than that obtained by Kaul et al. [34] and Kim et al. [35]. Kim and coworkers [37] used three methods to immobilize Ni-based $\alpha$-diimine catalysts on nonporous $\mathrm{SiO}_{2}$ covalently, without using any lengthy conventional processes. In the first method, a diimine ligand with an -OEt end-group reacted with - $\mathrm{OH}$ on the nonporous $\mathrm{SiO}_{2}$, eliminating one molecule of $\mathrm{EtOH}$, and then the metal compound was introduced. The second method was more common; the Ni-based $\alpha$-diimine catalysts were prepared and then immobilized on nonporous $\mathrm{SiO}_{2}$. The third method was based on the second one, but with the addition of tetraethyl orthosilicate during the synthesis. The different preparation methods affected the catalytic activity. The supported catalyst prepared by the first method had higher activity and thermostability, even when the $\mathrm{Al} / \mathrm{Ni}$ ratio was 
as low as 100 , and the highest activity of $10 \mathrm{~g}-\mathrm{PE} /(\mathrm{mol}-\mathrm{Ni}$ $\mathrm{Pa} \mathrm{h}$ ) was obtained. Nonporous $\mathrm{SiO}_{2}$ was used as a support, without any chemical or thermal treatments, which could save time.

Some researchers thought that noncovalent immobilization of LTM catalysts on $\mathrm{SiO}_{2}$ treated with alkylaluminum was the result of physisorption. A new series of Ni-based diimine catalysts with terphenyl structure were prepared by Wegner et al. [38] and immobilized on $\mathrm{SiO}_{2}$ treated with MAO; the author considered the loading method to be physisorption, and ascribed the leaching [39] of some catalysts from the support during polymerization to the low oxophilicity of LTMs. Gas-phase ethylene polymerization experiments showed that higher activities of up to $1 \mathrm{~g}-\mathrm{PE} /(\mathrm{g}-\mathrm{Ni} \mathrm{Pa}$ h) could be obtained. Scanning electron microscopy (SEM) analysis showed that the polymers replicated the morphology of the catalyst particles.

\subsection{Late-transition-metal catalysts immobilized on $\mathrm{MgCl}_{2}$ supports}

$\mathrm{MgCl}_{2}$ is another inorganic support commonly used in industry. $\mathrm{Xu}$ and coworkers [40] successfully immobilized $\mathrm{Ni}$-based $\alpha$-diimine complexes on spherical $\mathrm{MgCl}_{2}$ supports obtained by thermal dealcoholization of $\mathrm{MgCl}_{2} \cdot 2.56 \mathrm{C}_{2} \mathrm{H}_{5}$ $\mathrm{OH}$. The activity of the supported catalyst and the properties of the resultant polymers strongly depended on the dealcoholization temperature. By using catalysts on supports treated at $170^{\circ} \mathrm{C}$, activities even higher than those of homogeneous catalysts were obtained. In high-pressure ethylene polymerization, the activity reached $13 \mathrm{~g}-\mathrm{PE} /(\mathrm{mol}-\mathrm{Ni} \mathrm{Pa} h)$. The morphology of the resultant PE particles was spherical, which was similar to that of the $\mathrm{MgCl}_{2}$ support.

An effective method for the immobilization of Ni-based catalysts using spherical supports of composition $\mathrm{MgCl}_{2} /$ $\mathrm{AlR}_{n}(\mathrm{OEt})_{3-n}$ was reported by Severn and Chadwick [41]. $\mathrm{MgCl}_{2}$-supported catalysts for ethylene polymerization can have an activity of around $71.58 \mathrm{~g}-\mathrm{PE} /(\mathrm{mol}-\mathrm{Ni} \mathrm{Pa} \mathrm{h})$. Through a study of the resultant products and the polymerization mechanism, the authors considered that the support had an effect on chain-walking [42], resulting in higher degrees of branching in PE prepared by heterogeneous systems than had been reported for PE prepared using homogeneous systems. The branching degree of the PE increased with increasing size of the substituent groups at axial sites.

Huang et al. [43] successfully immobilized 2,6-bis(imino) pyridyl $\mathrm{Fe}, \mathrm{Cr}$, and $\mathrm{V}$ precatalysts on $\mathrm{MgCl}_{2} / \mathrm{AlR}_{n}(\mathrm{OET})_{3-n}$ supports. They studied the effects of different transition-metals on catalytic activity, molecular-weight, and molecular-weight distribution of the resultant PE, and found that the activities of heterogeneous systems were higher than those of homogeneous systems. The Fe-based catalyst gave an activity as high as $367.2 \mathrm{~g}-\mathrm{PE} /(\mathrm{mol}-\mathrm{Fe} \mathrm{Pa} \mathrm{h})$; the molecular-weight distribution of $\mathrm{PE}$ ranged from 3 to 12 with changes in the substituents at the 2,6-positions of the aryl groups in the ligand. Because of the nature of Cr-based catalysts, some of the catalyst was easily leached from the support to form multi-active centers during polymerization. Although higher molecular-weights than those of PE prepared using Fe-based supported catalysts could be obtained, leaching resulted in poor morphology. An unusual result was observed when the V-based catalysts were reacted with excess MAO. In this case, alkylation of the pyridine ring took place [44], so the PE prepared using V-based catalysts had narrow molecular-weight distributions. These characteristics were maintained after immobilization.

Using supported 2,6-bis(imino)pyridyl Fe catalysts for ethylene polymerization could avoid reactor fouling and improve the morphology of the resultant PE, but the low catalytic activity is still an unsolved problem, and is the result of limitations caused by slow monomer diffusion. Chadwick et al. [45] found that the diffusion limitation can be alleviated by introducing a comonomer; moreover, incorporating a Ni-based catalyst into an $\mathrm{MgCl}_{2}$-immobilized Fe-based system can lead to a significant decrease in the monomer diffusion limitation, thereby further increasing the activities of the Fe-based catalysts. Activity increases equivalent to around $30-40 \mathrm{~g}-\mathrm{PE} /(\mathrm{mol}-\mathrm{Fe} \mathrm{Pa}$ h) were obtained. The synergistic effect was obtained with relatively small quantities of the Ni-based catalysts, so the resultant products retained the characteristics of those prepared using Fe-based catalysts, and were essentially linear and high density.

The co-immobilization of metallocene catalysts which give high-molecular-weight $\mathrm{PE}$, and Fe-based $\alpha$-diimine catalysts which give low-molecular-weight $\mathrm{PE}$ on $\mathrm{MgCl}_{2}$ / $\mathrm{AlR}_{n}(\mathrm{OET})_{3-n}$ supports was investigated by Kukalyekar and coworkers [46]. Gel-permeation chromatography (GPC) analysis showed that the resultant polymer was bimodal PE, indicating that in this catalytic system there was no synergistic effect of co-immobilization on catalyst productivity, unlike the combination of metallocene catalysts and $\mathrm{Ni}$ based catalysts. The ratio of high- and low-molecularweight fractions depended on the amounts of the two catalysts. This approach resulted in an intimate bimodal blend of high- and low-molecular-weight PEs; the high-molecularweight component suppressed the nucleation barrier to form "shish-kebab" polymer morphology. This new synthetic route makes an improvement on the base of traditional methods of preparing bimodal PE.

Choi and Soares [47] treated $\mathrm{MgCl}_{2}$ /methanol with TMA to form the linking group $-\mathrm{AlMe}_{2}$, and then prepared $\mathrm{MgCl}_{2}$-supported Ni-based catalysts by the reaction of one or two $-\mathrm{NH}_{2}$ groups in the aryl groups of Ni-based diimine catalysts with $-\mathrm{AlMe}_{2}$ in the support (Figure 4).

Researchers used a homogeneous system, an $\mathrm{MgCl}_{2}-$ supported catalyst, and a $\mathrm{SiO}_{2}$-supported catalyst, respectively, to catalyze ethylene polymerization under the same conditions. The results showed that the activity of the $\mathrm{MgCl}_{2}$ supported catalyst was higher than that of the $\mathrm{SiO}_{2}$-sup- 


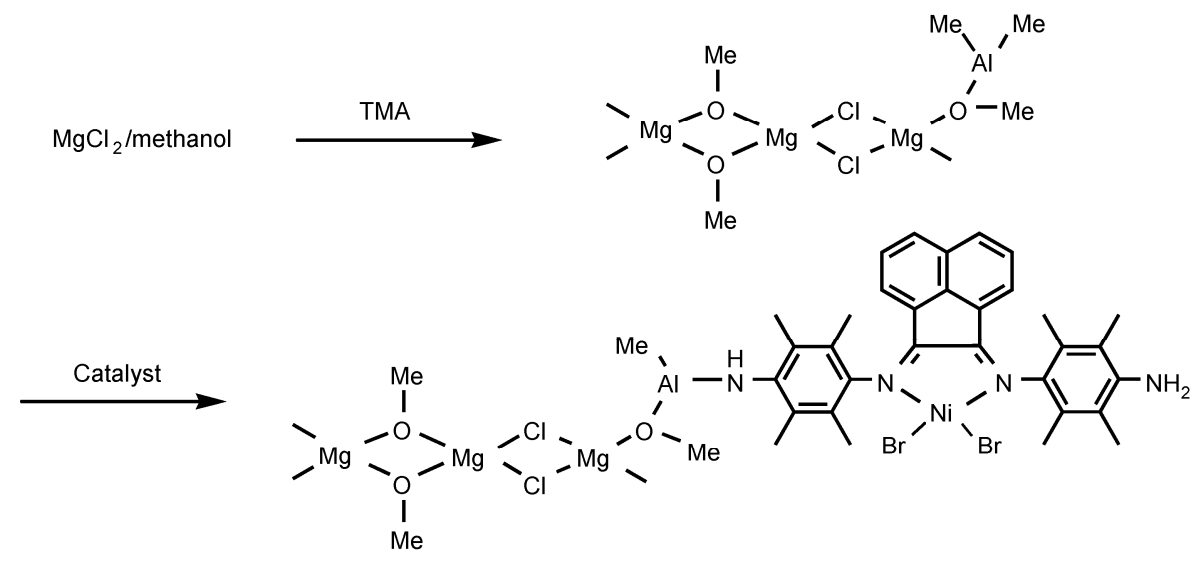

Figure 4 Preparation of $\mathrm{MgCl}_{2}$-supported catalyst.

ported catalyst, and was nearly $90 \%$ of that obtained under homogeneous conditions. The polymers made using the $\mathrm{MgCl}_{2}$-supported catalyst were free-flowing particles that did not cause reactor fouling, although they were weaker and more porous than those prepared using the corresponding $\mathrm{SiO}_{2}$-supported catalyst.

Jiang et al. [48] prepared a $\mathrm{SiO}_{2}-\mathrm{MgCl}_{2}$ bi-support by removing $\mathrm{HCl}$ generated from the reaction of $\mathrm{MgCl}_{2}$ with pretreated $\mathrm{SiO}_{2}$ (Scheme 1), and then immobilized a Nibased $\alpha$-diimine catalyst on the bi-support. The bi-supported catalyst could be used to polymerize ethylene, with high activity, using diethylaluminum chloride as an inexpensive cocatalyst, resulting in branched PE (100.9/1000C). SEM analysis showed that the polymers replicated the support morphology, indicating that the bi-supported catalyst had a uniform distribution of active sites and high porosity.

$\mathrm{Si}-\mathrm{OH}+\mathrm{MgCl}_{2} \cdot n \mathrm{EtOH} \longrightarrow \mathrm{SiOMgCl} \cdot n \mathrm{EtOH}+\mathrm{HCl}$

Scheme 1 Formation mechanism of $\mathrm{SiO}_{2}-\mathrm{MgCl}_{2}$ bi-support.

\subsection{Late-transition-metal catalysts immobilized on other inorganic supports}

Besides $\mathrm{SiO}_{2}$ and $\mathrm{MgCl}_{2}$, some other inorganic materials with special structures, such as mica, molecular sieves, and palygorskite, can be used to immobilize catalysts. Different loading methods were used for various supports.

Kurokawa et al. [49] chose fluorotetrasilicic mica with an interlayer space structure as a support for Fe-based diimine catalysts. X-ray diffraction (XRD) and thermogravimetric-differential thermal analysis of the supported catalysts confirmed the loading mechanism. $\mathrm{Fe}^{3+}$ was immobilized in the interlayer spaces of the mica through $\mathrm{Na}^{+}$-mica ionexchange reactions, and then bis(imino)pyridyl ligands intercalated into the LTM ion-exchanged clay mineral interlayers. The catalytic activities of mica-supported catalysts decreased with increasing steric bulk of the substituent groups since sterically bulky ligands have difficulty inter- calating into the mica interlayers.

Nanocomposites synthesized from silicates such as montmorillonoids and clays have been studied extensively. The extension strengths and heat resistances of the nanocomposites were higher than those of the original polymers or other materials mixed with silicates [50,51]. Rong et al. $[52,53]$ were the first to use palygorskite clay as the support for Ziegler-Natta catalysts to produce PE/clay nanocomposites. The palygorskite provided a new environment as a result of clustering of palygorskite nanofibers, which provided a large surface area and strong adsorptive capacity. Yan et al. [54] immobilized Ni-based diimine catalysts on palygorskite and on palygorskite pretreated with MAO. Transmission electron microscopy showed that after MAO treatment, the densely packed nanofibers evolved into numerous nanofiber clusters consisting of single fibers. An inductively coupled plasma-atomic emission spectroscopy examination of the supported catalysts indicated that the MAO pretreatment improved the catalyst loading and resulted in high catalytic activity. Although the activity was lower than that of homogeneous systems, it was higher than that of $\mathrm{SiO}_{2}$-supported catalysts. The polymerization of ethylene was initiated on the active sites at the fiber surface and then PE encapsulated palygorskite fibers to form capsules. Finally, the PE/palygorskite nanocomposite was obtained.

Ni-based diimine catalysts with $-\mathrm{NH}_{2}$ in the aryl groups of the ligands were prepared by Choi et al. [55], and they immobilized the catalysts on montmorillonite (MMT) with organic modifiers. The activities of MMT-supported catalysts were higher than those of homogeneous systems. The catalytic activities of the supported catalysts were almost the same, whether or not there were cocatalysts present. When the polymerization time was prolonged to $9 \mathrm{~h}$, the activity of the system in the absence of cocatalysts increased 1.5-fold. XRD revealed that particle intercalation and exfoliation were initiated by the insertion of Ni-based diimine complexes into MMT galleries. SEM and TEM micrographs confirmed the formation of a nanophase of 
MMT layers distributed in the polymer matrix, and showed polymer fibrils that seemed to grow from the surfaces of the clay platelets.

In recent years, molecular sieves have been used as supports for olefin polymerization catalysts. Guo et al. [56] immobilized LTM complexes capable of oligomerizing ethylene to $\alpha$-olefins, and metallocene catalysts that could catalyze copolymerization of ethylene and $\alpha$-olefins, on mesoporous molecular sieves (MCM-41 and SBA-15). The activities obtained using the molecular-sieve-supported $\mathrm{Fe}$ based diimine catalysts in the absence of MAO were higher than those obtained using homogeneous systems, up to 43.5 $\mathrm{g}-\mathrm{PE} /(\mathrm{mol}-\mathrm{Fe} \mathrm{Pa}$ h). The selectivity for lower $\alpha$-olefins $\left(\mathrm{C}_{4}-\mathrm{C}_{10}\right)$ increased significantly as a result of restriction of the molecular sieve pore size. The two-catalyst system can use ethylene as the only raw material in the preparation of linear low-density PE (LLDPE) possessing a suitable degree of branching, high molecular-weight, and broad molecularweight distribution. The MCM-41-supported catalyst system produced LLDPE with the best physical and mechanical properties, partly because of the distribution of molecular sieves in the LLDPE structure during polymerization; this resulted in the formation of a uniform and stable structure, and PE that had excellent shear-thinning behavior and a high storage modulus. Molecular-sieve-supported hybrid catalysts were prepared by $\mathrm{Li}$ et al. [57] through immobilizing a Ni-based diimine catalyst and a $\mathrm{Cp}_{2} \mathrm{TiCl}_{2}$ catalyst on MCM-41 molecular sieves. The catalytic properties of the catalyst with two types of active site were investigated at low $\left(0^{\circ} \mathrm{C}\right)$ and high $\left(50^{\circ} \mathrm{C}\right)$ temperatures. MCM-41 provided a constrained nanoscale chemical environment that limited the distribution of the ethylene monomer, resulting in lower catalytic activity than that of homogeneous systems. The Ni-based diimine catalyst and $\mathrm{Cp}_{2} \mathrm{TiCl}_{2}$ catalyst produced linear PE and branched PE, respectively, and the supported hybrid catalyst improved the miscibilities of the polymer blends. The SEM results showed that the miscibility of the polymers obtained at $50^{\circ} \mathrm{C}$ was the best; no phase separation was observed.

Currently, most reports are of direct immobilization of LTM complexes on molecular sieves, which does not completely avoid leaching. Supporting LTM catalysts on molecular sieves via covalent bonds can not only effectively avoid leaching, but can also provide polymer-grafted molecular sieves with improved mechanical properties. Xu et al. [58] tried many LTM catalysts, and finally succeeded in immobilizing a Brookhart Pd-diimine catalyst on molecular sieves (SBA-15 and MSU-F) with acryloyl through covalent bonds (Scheme 2). This is the first report of the preparation of PE-grafted molecular sieves using a supported LTM catalyst. The active sites are distributed in the pore canals of the molecular sieves, and this prevents highly branched PE from blocking the pore canals. Thermogravimetric and $\mathrm{N}_{2}$ adsorption-desorption analyses of the resultant polymers showed fast formation of long polymer grafts close to the pore openings as a result of the high activity of the Pdcatalyzed ethylene polymerization; these grafts blocked the pore openings and restricted further monomer diffusion. This phenomenon was more apparent for the SBA-15-supported catalyst. The amount of grafted PE in the composite increased with increasing polymerization time.

\section{Late-transition-metal catalysts immobilized on organic carriers}

Since the catalyst can remain in the polymer product when inorganic carriers are used, the residues may affect the optical and mechanical properties of the final products $[59,60]$. To avoid such drawbacks, replacing inorganic supports with organic materials with special structures has been investigated in industry and by academics.

$\mathrm{Li}$ et al. [61] modified $\alpha$-diimine ligands containing allyl groups with chlorodimethylsilane to introduce reactive $\mathrm{Si}-\mathrm{Cl}$ end-groups, enabling their immobilization via a direct reaction of the $\mathrm{Si}-\mathrm{Cl}$ groups with - $\mathrm{OH}$ groups on an ethanolamine-modified Merrifield resin. After coordination of the immobilized ligand with $\mathrm{NiBr}_{2}$, resin-supported $\mathrm{Ni}$-based diimine catalysts were obtained. The corresponding $\mathrm{SiO}_{2-}$ supported catalysts were prepared for comparison. It was found that the Ni loadings of the modified Merrifield resin were much higher than those of $\mathrm{SiO}_{2}$. The catalysis behaviors of the Merrifield-resin-supported catalysts in the presence of MAO were similar to those of the silica-supported catalysts, but with lower activities. Both catalytic systems avoided reactor fouling well.

Xia et al. [62] first synthesized hyperbranched PEs bearing different numbers of pendant acryloyl groups by nonliving chain-walking copolymerization of ethylene with 1,4-butanediol diacrylate. Hyperbranched polymers with specific acryloyl anchoring sites could be used as supports for covalent immobilization of Pd-based diimine catalysts to

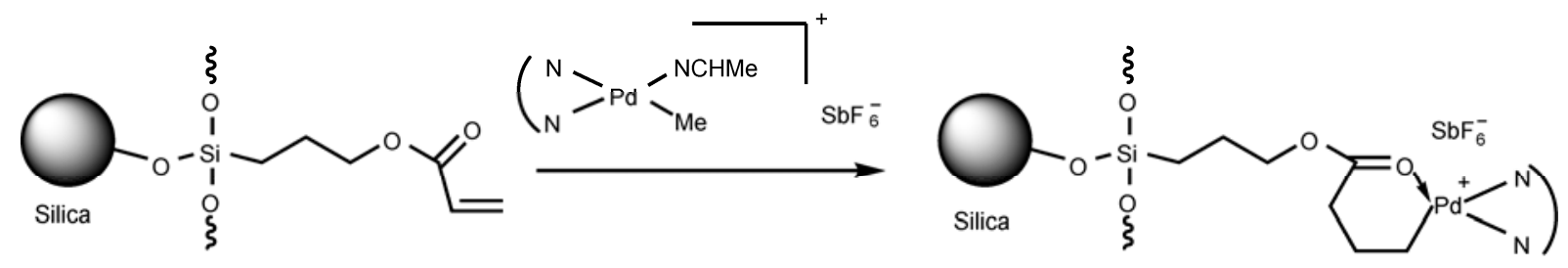

Scheme 2 Formation of supported Pd-diimine catalyst. 
generate hyperbranched PEs encapsulating multinuclear covalently tethered Pd-based diimine catalysts. These catalysts were used to catalyze ethylene multifunctional "living" polymerization at $2.75 \mathrm{MPa}$ and $5^{\circ} \mathrm{C}$, and led to simultaneous multidirectional arm growth from the hyperbranched core to form star polymers with very high molecularweights. Alkaline hydrolysis experiments were carried out to cleave the arms from the hyperbranched PE core. GPC analysis of the polymer arms indicated a narrow polydispersity index (about 1.0). The molecular-weights of the polymer stars increased linearly with increasing polymerization time. The intrinsic viscosities of these star polymers were found to depend on the arm length rather than on the average arm number.

Although organic supports such as gel-type polystyrene and arborization polymers are effective for ethylene polymerization, and yield PE beads, their synthesis generally requires sophisticated pathways, which may limit their potential for industrial applications. Bouilhac and coworkers [63] investigated a new type of organic support based on a self-assembled copolymer of polystyrene and poly(4vinylbenzoic acid), and immobilized Fe-based diimine catalysts on the novel support. Ethylene polymerization was carried out at an ethylene pressure of $1 \times 10^{5} \mathrm{~Pa}$ at $30^{\circ} \mathrm{C}$. The highest activity obtained was $29.8 \mathrm{~g}-\mathrm{PE} /(\mathrm{mol}-\mathrm{Fe} \mathrm{Pa} \mathrm{h})$, when the $\mathrm{Al} / \mathrm{Fe}$ ratio was 325 . SEM images of the $\mathrm{PE}$ showed the formation of spherical particles of average diameters between $400 \mathrm{~nm}$ and $2 \mu \mathrm{m}$. The formation of a small amount of low molar-mass particles was attributed to some homogeneous polymerization that occurred as a side reaction. Heurtefeu et al. [64] performed the anionic polymerization of isoprene in cyclohexane, initiated by $s$-BuLi, and quenched the reaction by adding benzophenone to obtain diphenylhydroxy-terminated polyisoprene $\left(\mathrm{PI}-\phi_{2} \mathrm{OH}\right)$. The effects of MAO and TMA addition on $\mathrm{PI}-\phi_{2} \mathrm{OH}$ were investigated by dynamic light scattering. The addition of TMA led to an increase in the particle size, with no formation of larger aggregates, whereas the addition of MAO increased the particle size through the formation of larger aggregates. PI- $\phi_{2} \mathrm{OH}$ with a micellar structure was used to support the tridentate bis(imino)pyridyl Fe catalyst and a Ni-based diimine catalyst. The effect of the support on the production of $\mathrm{PE}$ using a $\mathrm{PI}-\phi_{2} \mathrm{OH}$-supported $\mathrm{Fe}$ based catalyst was investigated; with MAO, the activity of the PI- $\phi_{2} \mathrm{OH} / \mathrm{Fe}$ catalytic system reached $29.87 \mathrm{~g}-\mathrm{PE} /(\mathrm{mol}-$ $\mathrm{Fe} \mathrm{Pa}$ h), which was higher than that of the $\mathrm{PI}-\phi_{2} \mathrm{OH} / \mathrm{Ni}$ system and a homogeneous system. The resultant PE particle size was strongly affected by the PE microstructure (linear or branched). Amorphous branched PE yielded large PE particles as a result of the effect of chain-walking at high temperature. A low temperature restricted chain-walking, leading to small PE particles.

A convenient one-pot method for covalently tethering an amino-functionalized Ni-based diimine catalyst to a spherical periodic mesoporous organosilica (SPMO) was reported by Bahuleyan et al. [65]. Since this one-pot method reduced the number of lengthy and sensitive preparation steps, it has good industrial potential. The SPMO-supported catalyst catalyzed ethylene polymerization with high activity $[>10$ g-PE)/(mol-Ni Pa h)]. TEM and SEM analyses of the PE showed that the resultant products had excellent morphologies as a result of replicating the catalyst morphology.

Hošt'álek et al. [66] prepared polybutadiene (PBD) with aliphatic carboxylic acid end-groups (PBD-MA and PBD-TRIMA) by reactions of PBD-OH groups with maleic anhydride (MA) and trimesoyl chloride (TRIMA) (Scheme 3).

The high polarity of MAO had a positive effect on the self-assembly of PBD-MA, which increased the polarity of the system, leading to more stable particles. Different catalytic systems were used to catalyze ethylene polymerization under the same conditions; the activity order was PBDMA > PBM-TRIMA > homogeneous system. Low Al/Ni ratios resulted in poor morphologies. SEM analysis of the polymers revealed that in the case of homogeneous polymerization, the particles were connected by fibers and formed clusters, which increased the viscosity, producing a negative influence on agitation. When supports were used, the micellar structures of the supports restricted the formation of branched PE, leading to the formation of a crystalline phase; this was confirmed by the higher melting temperatures and higher heats of fusion of the polymers.
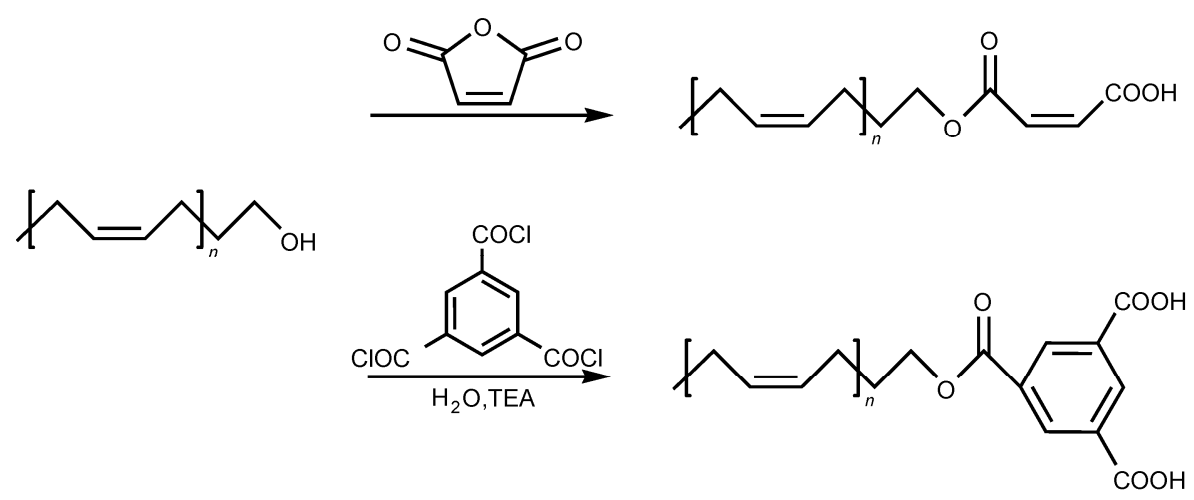

Scheme 3 Synthesis of PBD-MA and PBD-TRIMA. 


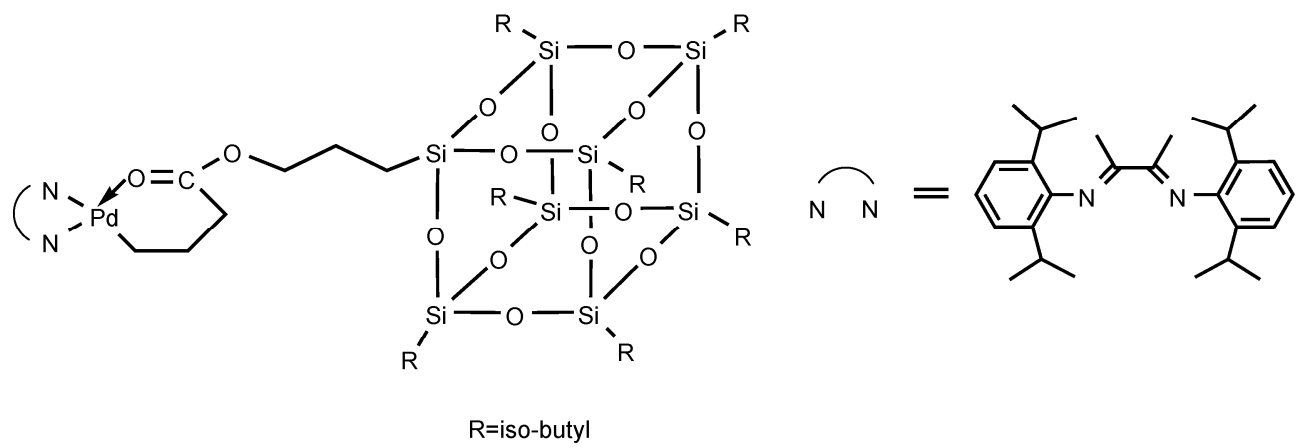

Figure 5 POSS-supported Pd-based diimine catalyst.

\section{Late-transition-metal catalysts immobilized on inorganic-organic composites}

The novel inorganic-organic composites not only possess the advantages of organic materials, such as excellent processability, toughness, and low cost, but they also retain the heat and oxidation resistances of inorganic materials. In addition, the constituents of inorganic-organic composites can be easily controlled, which is convenient for the design and clipping of materials. As a result of their many advantages, novel inorganic-organic composites have the potential for applications in many fields.

Polyhedral oligomeric silsesquioxane (POSS) has recently received much attention as a nanoscale building block, and various polymers containing covalently tethered POSS nanoparticles have been synthesized [67]. Zhang and Ye [68] reported a novel POSS-supported Pd-based diimine catalyst (Figure 5). For loading of the Pd-based diimine catalyst, a POSS bearing acrylate functionalities was chosen. The ethylene polymerization results showed that the molecular-weights of the polymers increased linearly with polymerization time, and the polydispersity index values were low (1.11-1.19). ${ }^{1} \mathrm{H}$ NMR spectra showed that the polymers were highly branched (88/1000C). Differential scanning calorimetry and XRD analyses indicated that POSS was present in the resultant polymers and showed the effects of POSS on the polymers.

\section{Summary}

Supported LTM catalysts offer new opportunities in the development of the polyolefin industry. The immobilization of LTM catalysts can not only prolong the catalyst age (some increase the activity) and stabilize the polymerization reaction, but can also void the difficulties of slow heat dissipation and reactor fouling during polymerization. The particle morphologies and processabilities of polymers prepared using supported catalysts were significantly better than those of polymers prepared using homogeneous systems. By co-immobilizing LTM catalysts with other cata- lysts on the same support, and combining their respective catalytic properties, we can produce bimodal polyethylene or produce LLDPE using ethylene as the sole feedstock. The choice of supports that could retain (or even increase) the activities of LTM catalysts will continue to be a hot research topic. More research should focus on better applications to industrial slurry and gas-phase polymerizations, which are important in accelerating the use of LTM catalysts in industrial processes.

This work was supported by the National Natural Science Foundation of China (20972025), the China National Petroleum Corporation (CNPC) Innovation Foundation (2010D-5006-0504), Scientific Research Foundation for the Returned Overseas Chinese Scholars, Heilongjiang Province (41417837-8-08016) and Scientific Research Foundation for Overseas Chinese Scholars, Department of education of Heilongjiang Province (1154H14).

1 Kaminsky W, Külper K, Brintzinger H H, et al. Polymerization of propene and butene with a chiral zirconocene and methylalumoxane as cocatalyst. Angew Chem Int Ed, 1985, 24: 507-508

2 Brintzinger H H, Fischer D, Mulhaupt R, et al. Stereospecific olefin polymerization with chiral metallocene catalysts. Angew Chem Int Ed, 1995, 34: 1143-1170

3 Coates G W, Waymouth R M. Oscillating stereocontrol in the polymerization of propylene: A new strategy for the synthesis of thermoplastic elastomeric polypropylene. Science, 1995, 267: 217218

4 Johnson L K, Killian C M, Brookhart M. New Pd(II)-based and $\mathrm{Ni}(\mathrm{II})$-based catalysts for polymerization of ethylene and alpha-oleins. J Am Chem Soc, 1995, 117: 6414-6415

5 Britocsek G J P, Gibson V C, Wass D F. The search for new-generation olefin polymerization catalysts: Life beyond metallocenes. Angew Chem Int Ed, 1999, 38: 428-447

6 Ittel S D, Johnson L K, Brookhart M. Late-metal catalysts for ethylene homo- and copolymerization. Chem Rev, 2000, 100: 11691203

7 Gibson V C, Spitzmesser S K. Advances in non-metallocene olefin polymerization catalysis. Chem Rev, 2003, 103: 283-315

8 Guan Z B, Popeney C S. Recent progress in late transition metal $\alpha$-diimine catalysts for olefin polymerization. Top Organomet Chem, 2009, 26: 179-220

9 Zhao W Z, Yu J G, Song S J, et al. Controlling the ethylene polymerization parameters in iron pre-catalysts of the type 2-[1-(2,4dibenzhydryl-6-methylphenylimino)ethyl]-6-[1-(arylimino)ethyl] pyridyliron dichloride. Polymer, 2012, 53: 130-173

10 Bahuleyan B K, Lee K J, Lee S H, et al. Trinuclear Fe(II)/Ni(II) complexes as catalysts for ethylene polymerizations. Catal Today, 
2011, 164: 80-87

11 Zhang W J, Chai W B, Sun W H, et al. 2-(1-Arylimino)ethyl)-8arylimino-567-trihydro-quinoline iron(II) chloride complexes: Synthesis characterization and the ethylene polymerization behavior. Organometallics, 2012, 31: 5039-5048

12 Guo L H, Gao H Y, Zhang L, et al. An unsymmetrical iron(II) bis(imino)pyridyl catalyst for ethylene polymerization: Effect of a bulky ortho substituent on the thermostability and molecular weight of polyethylene. Organometallics, 2010, 29: 2118-2125

13 He F, Zhao W Z, Cao X P, et al. 2-[1-(26-Dibenzhydryl-4-chlorophenylimino)ethyl]-6-[1-aryliminoethyl] pyridylcobalt dichlorides: Synthesis characterization and ethylene polymerization behavior. J Organomet Chem, 2012, 713: 209-216

14 Lai J J, Zhao W Z, Yang W H, et al. 2-[1-(24-Dibenzhydryl-6methylphenylimino)ethyl]-6-[1-(arylimino)ethyl]pyridyl cobalt(II) dichlorides: Synthesis characterization and ethylene polymerization behavior. Polym Chem, 2012, 3: 787-793

15 Liu H, Zhao W Z, Sun W H, et al. Synthesis, characterization and ethylene polymerization behavior of nickel dihalide complexes bearing bulky unsymmetrical $\alpha$-diimine ligands. Catal Sci Technol, 2012, 2: $415-422$

16 Hou X H, Cai Z G, Chen X, et al. $N$-(5,6,7-Trihydroquinolin-8ylidene)-2-benzhydrylbenzenaminonickel halide complexes: Synthesis, characterization and catalytic behavior towards ethylene polymerization. Dalton Trans, 2012, 41: 1617-1623

17 Sun W H, Song S J, Li B X, et al. Ethylene polymerization by 2iminopyridylnickel halide complexes: Synthesis characterization and the catalytic influence of the benzhydryl group. Dalton Trans, 2012, 41: 11999-12010

18 Yu J G, Hu X Q, Zeng Y N, et al. Synthesis, characterisation and ethylene oligomerization behaviour of $N$-(2-substituted-5,6,7trihydroquinolin-8-ylidene)arylaminonickel dichlorides. New J Chem, 35: 178-183

19 Yu J G, Zeng Y N, Huang W, et al. N-(5,6,7-Trihydroquinolin-8ylidene)arylaminonickel dichlorides as highly active single-site procatalysts in ethylene polymerization. Dalton Trans, 2011, 40: 8436-8443

20 Zhang L P, Hao X, Sun W H, et al. Synthesis, characterization and ethylene polymerization behavior of 8-(nitroarylamino)-5,6,7-trihydroquinolylnickel dichlorides: Influence of the nitro group and impurities on catalytic activity. ACS Catal, 2011, 1: 1213-1220

21 Liu H, Zhao W Z, Hao X, et al. 2,6-Dibenzhydryl- $N$-(2-phenyliminoacenaphthylenyl-idene)-4-methylbenzenamine nickel dibromides: Synthesis, characterization and ethylene polymerization. Organometallics, 2011, 30: 2418-2414

22 Guo L H, Gao H Y, Guan Q R, et al. Substituent effects of the backbone in $\alpha$-diimine palladium catalysts on homo- and copolymerization of ethylene with methyl acrylate. Organometallics, 2012, 31: 6054-6062

23 Popeney C S, Levins C M, Guan Z B. Systematic investigation of ligand substitution effects in cyclophane-based nickel(II) and palladium(II) olefin polymerization catalysts. Organometallics, 2011, 30: 2432-2452

24 Bahuleyan B K, Ahn I Y, Appukuttan V, et al. Ethylene oligomerization by tridentate cobalt complexes bearing pendant donor modified $\alpha$-diimine ligands. Macromol Res, 2010, 18: 701-704

25 Liu F S, Gao H Y, Hu Z L, et al. Poly(1-hexene) with long methylene sequences and controlled branches obtained by a thermostable $\alpha$-diimine nickel catalyst with bulky camphyl backbone. J Polym Sci Part A: Polym Chem, 2012, 50: 3859-3866

26 Welborn Jr H C. Supported polymerization catalyst. US Patent, 4701 432, 1987-10-20

$27 \mathrm{Xu} \mathrm{H}$, Guo C, Xue C F, et al. Novel layered calcosilicate-immobilized iron-based diimine catalyst for ethylene polymerization. Eur Polym J, 2006, 42: 203-208

28 Ma Z, Ye Y, Wang H, et al. Ethylene polymerization with a silicasupported iron-based diimine catalyst. J Appl Polym Sci, 2003, 88: 466-469

29 Soga K, Kim H J, Shiono T. Polymerization of propene with highly isospecific. $\mathrm{SiO}_{2}$-supported zirconocene catalysts activated with common alkylaluminiums. Macromol Chem Phys, 1994, 195: 33473360

30 Tian J, Metcalfe R, Feng Y D, et al. Synthesis of and olefin polymerization using tethered, ansa-metallocene complexes. Macromolecules, 2001, 34: 3120-3122

31 Hicks J C, Mullis B A, Jones C W. An organic/inorganic hybrid cocatalyst capable of activating metallocenes for the synthesis of polyolefins. J Am Chem Soc, 2007, 129: 8426-8427

32 Schrekker H S, Kotov V, Preishuber-Pflugl P, et al. Efficient slurry-phase homopolymerization of ethylene to branched polyethylenes using $\alpha$-diimine nickel(II) catalysts covalently linked to silica supports. Macromolecules, 2006, 39: 6341-6354

33 Choi Y, Soares J B P. Synthesis of supported nickel diimine catalysts for ethylene slurry polymerization. Macromol Chem Phys, 2009, 210: 1979-1988

34 Kaul F A R, Puchta G T, Schneider H, et al. Immobilization of bis(imino)pyridyl iron(II) complexes on silica. Organometallics, 2002, 21: 74-82

35 Kim I, Han B H, Ha C S, et al. Preparation of silica-supported bis(imino)pyridyl iron(II) and cobalt(II) catalysts for ethylene polymerization. Macromolecules, 2003, 36: 6689-6691

36 Zheng Z J, Liu J Y, Li Y S. Ethylene polymerization with silicasupported bis(imino)pyridyl iron(II) catalysts. J Catal, 2005, 234: 101-110

37 Bahuleyan B K, Son B C, Ha Y S, et al. Leaching- and fragmentation-free heterogenization of late transition metal complexes as a model system to prove the growth mechanism of polyethylene. J Mater Chem, 2010, 20: 7150-7157

38 Wegner M M, Anna K Ott, Rieger B. Gas phase polymerization of ethylene with supported $\alpha$-diimine nickel(II) catalysts. Macromolecules, 2010, 43: 3624-3633

39 Tannous K, Soares J B P. Gas phase polymerization of ethylene gas phase polymerization of ethylene using supported metallocene catalysts: Study of polymerization conditions. Macromol Chem Phys, 2002, 203: 1895-1905

$40 \mathrm{Xu} \mathrm{R} \mathrm{W,} \mathrm{Liu} \mathrm{D} \mathrm{B,} \mathrm{Wang} \mathrm{S} \mathrm{B,} \mathrm{et} \mathrm{al.} \mathrm{Preparation} \mathrm{of} \mathrm{spherical} \mathrm{MgCl}_{2}$ supported late-transition metal catalysts for ethylene polymerization. Macromol Chem Phys, 2006, 207: 779-786

41 Severn J R, Chadwick J C. $\mathrm{MgCl}_{2}$-based supports for the immobilization and activation of nickel diimine catalysts for polymerization of ethylene. Macromolecules, 2004, 37: 6258-6259

42 Möhring V M, Neuartige F G. Polymerisation von $\alpha$-olefinen mit dem katalysatorsystem nickel/aminobis(imino)phosphoran. Angew Chem, 1985, 97: 982-985

43 Huang R B, Kukalyekar N, Koning C E, et al. Immobilization and activation of 2,6-bis(imino)pyridyl $\mathrm{Fe}, \mathrm{Cr}$ and $\mathrm{V}$ precatalysts using a $\mathrm{MgCl}_{2} / \mathrm{AlRn}(\mathrm{OEt})_{3-n}$ support: Effects on polyethylene molecular weight and molecular weight distribution. J Mol Catal A Chem, 2006, 260: $135-143$

44 Reardon D, Conan F, Gambarotta S, et al. Life and death of an active ethylene polymerization catalyst. Ligand involvement in catalyst activation and deactivation. Isolation and characterization of two unprecedented neutral and anionic vanadium(I) alkyls. J Am Chem Soc, 1999, 121: 9318-9325

45 Chadwick J C, Huang R B, Kukalykar N, et al. Ethylene polymerization with combinations of early- and late-transition metal catalysts immobilized on $\mathrm{MgCl}_{2}$ supports. Macromol Symp, 2007, 260: 154160

46 Kukalyekar N, Luigi B, Gerrit W M P, et al. Characteristics of bimodal polyethylene prepared via co-immobilization of chromium and iron catalysts on $\mathrm{MgCl}_{2}$-based support. Macromol React Eng, 2009, 3: $448-454$

47 Choi Y, Soares J B P. Ethylene slurry polymerization using nickel diimine catalysts covalently-attached onto $\mathrm{MgCl}_{2}$-based supports. Polymer, 2010, 51: 2271-2276

48 Jiang H L, Li J S, Wang F J. Polymerization of ethylene using a nickel $\alpha$-diimine complex covalently supported on $\mathrm{SiO}_{2}-\mathrm{MgCl}_{2}$ bisupport. Polym Bull, 2010, 65: 767-777 
49 Kurokawa H, Matsuda M, Fujii K J, et al. Bis(imino)pyridine iron and cobalt complexes immobilized into interlayer space of fluorotetrasilicic mica: Highly active heterogeneous catalysts for polymerization of ethylene. Chem Lett, 2007, 36: 1004-1005

50 Suprakas S R, Masami O. Polymer/layered silicate nanocomposites: A review from preparation to processing. Prog Poly Sci, 2003, 28, 1539-1641

51 Arimitsu U, Yoshitsugu K, Masaya K. Synthesis of nylon 6-clay hybrid. J Mater Res, 1993, 8: 1179-1184

52 Rong J F, Jing Z H. A polyethylene nanocomposite prepared via in-situ polymerization. Macromol Rapid Commun, 2001, 22: 329334

53 Rong J F, Li H Q, Jing Z H, et al. Novel organic/inorganic nanocomposite of polyethylene. I. Preparation in-situ polymerization approach. J Appl Polym Sci, 2001, 82: 1829-1837

54 Yan X W, Wang J D, Yang Y R, et al. Ethylene polymerization with palygorskite supported nickel-diimine catalyst. Chin J Chem Eng, 2005, 13: 361-366

55 Choi Y, Sang Young A S, Soares J B P. Preparation of polyethylene/montmorillonite nanocomposites through in situ polymerization using a montmorillonite-supported nickel diimine catalyst. Macromol Chem Phys, 2010, 211: 1026-1034

56 Guo C Y, Xu H, Zhang M G, et al. Copolymerization of ethylene and in situ generated $\alpha$-olefins to high-performance linear low-density polyethylene with a two-catalyst system supported on mesoporous molecular sieves. Polym Int, 2010, 59: 725-732

57 Li W, Wang J D, Jiang B B, et al. Ethylene polymerization with hybrid nickel diimine/ $\mathrm{Cp}_{2} \mathrm{TiCl}_{2}$ catalyst: A new method to prepare blends of linear and branched polyethylene. Polym Int, 2010, 59: 617-623

58 Xu LX, Ye Z B, Cui Q Z, et al. Surface-initiated catalytic ethylene polymerization within nano-channels of ordered mesoporous silicas for synthesis of hybrid silica composites containing covalently tethered polyethylene. Polymer, 2011, 52: 5961-5974

59 Fink G, Steinmentz B, Zechlin J, et al. Propene polymerization with silica-supported metallocene/MAO catalysts. Chem Rev, 2000, 100: 1377-1390

60 Ferrero M A, Chiovetta M G. Catalyst fragmentation during propylene polymerization: Part I. The effects of grain size and structure. Polym Eng Sci, 1987, 27: 1436-1447

61 Li Y G, Pan L, Zheng Z J, et al. Polymerization of ethylene to branched polyethylene with silica and merrifield resin supported nickel(II) catalysts with $\alpha$-diimine ligands. J Mol Catal A Chem, 2008, 287: 57-64

62 Xia X W, Ye Z B, Morgan S, et al. "Core-first" synthesis of multiarm star polyethylenes with a hyperbranched core and linear arms via ethylene multifunctional "living" polymerization with hyperbranched polyethylenes encapsulating multinuclear covalently tethered Pddiimine catalysts. Macromolecules, 2010, 43: 4889-4901

63 Bouilhac C, Cloutet E, Taton D, et al. Block copolymer micelles as nanoreactors for single-site polymerization catalysts. J Polym Sci Part A: Polym Chem, 2009, 47: 197-209

64 Heurtefeu B, Merna J, Ibarboure E, et al. Organic support for ethylene polymerization based on the self-assembly in heptane of end-functionalized polyisoprene. Polym Chem, 2010, 1: 1078-1085

65 Bahuleyan B K, Jermy B R, Ahn I Y, et al. One-pot synthesis of spherical periodic mesoporous organosilica supported catalyst bearing $\mathrm{Ni}$ (II) $\alpha$-diimine complexes for ethylene polymerization. Catal Commun, 2009, 11: 252-256

66 Hošt'álek Z, Merna J, Heurtefeu B, et al. Control of morphology in olefin polymerization catalyzed by nickel diimine complexes encapsulated into polybutadiene based support. Polym Chem, 2012, 3: 658-667

67 Pielichowski K, Njuguna J, Janowski B, et al. Polyhedral oligomeric silsesquioxanes (POSS)-containing nanohybrid polymers. Adv Polym Sci, 2006, 201: 225-296

68 Zhang Y W, Ye Z B. Homogeneous polyhedral oligomeric silsesquioxane (POSS)-supported Pd-diimine complex and synthesis of polyethylenes end-tethered with a POSS nanoparticle via ethylene "living" polymerization. Chem Commun, 2008, 10: 1178-1180

Open Access This article is distributed under the terms of the Creative Commons Attribution License which permits any use, distribution, and reproduction in any medium, provided the original author(s) and source are credited. 